\title{
2-Arachodonoylglycerol-mediated endocannabinoid signaling modulates mechanical hypersensitivity associated with alcohol withdrawal in mice
}

\author{
Amanda Morgan ${ }^{1}$, Danielle Adank ${ }^{2}$, Keenan Johnson, Emily Blunt ${ }^{3}$, Sachin Patel ${ }^{1 \#}$ \\ ${ }^{1}$ Department of Psychiatry and Behavioral Sciences, Northwestern University Feinberg School of \\ Medicine, Chicago, IL 60611, USA \\ ${ }^{2}$ Vanderbilt Brain Institute, Vanderbilt University, Nashville, TN, USA \\ ${ }^{3}$ Interdisciplinary Program in Neuroscience for Undergraduates, Vanderbilt University, Nashville, \\ TN, USA \\ \#Corresponding Author: \\ Sachin Patel MD PhD \\ Lizzie Gilman Professor \\ Department of Psychiatry and Behavioral Sciences \\ Northwestern University \\ Feinberg School of Medicine \\ sachin.patel@northwestern.edu
}

Short Title: Endocannabinoids modulate pain during alcohol withdrawal

Keywords: CB1, CB2, pain, analgesia, cannabinoid, addiction 


\begin{abstract}
Alcohol use disorder (AUDs) commonly co-occurs in patients with chronic pain, and a major barrier to achieving abstinence and preventing relapse is the emergence of hyperalgesia during alcohol withdrawal. Elucidating novel therapeutic approaches to target hyperalgesia associated with alcohol withdrawal could have important implications for the treatment of AUD. Here we examined the role of 2-arachidonoylglycerol (2-AG)-mediated endocannabinoid (eCB) signaling in the regulation of hyperalgesia associated with alcohol withdrawal in mice and tested the hypothesis that pharmacological augmentation of 2-AG signaling could reduce hyperalgesia during withdrawal. After 72 hours of withdrawal from a continuous access two-bottle choice drinking paradigm, male and female mice exhibited increased mechanical but not thermal hypersensitivity, which normalized by 7 days. This effect was reversed by pretreatment with the monoacylglycerol lipase (MAGL) inhibitor JZL184, which elevates levels of 2-AG. The effects of JZL184 were prevented by coadministration of either a CB1 or CB2 antagonist. Inhibition of the 2-AG synthetic enzyme diacylglycerol lipase (DAGL) with DO34 exacerbated mechanical hypersensitivity during alcohol withdrawal, causing an earlier onset and persistent hypersensitivity even one week into withdrawal. Our findings demonstrate the critical role of 2-AG signaling in the bidirectional regulation of mechanical sensitivity during alcohol withdrawal, with enhancement of 2-AG levels reducing sensitivity, and inhibition of 2-AG synthesis exacerbating sensitivity. These data suggest 2-AG augmentation could represent a novel approach to the treatment of alcohol withdrawal-associated hyperalgesia and AUD in patients with comorbid pain disorders.
\end{abstract}




\section{INTRODUCTION}

The lifetime prevalence of alcohol use disorders (AUDs) is $\sim 30 \%$ in the U.S. population [1], with an estimated 15.5 million U.S. adults suffering from AUDs [2]. Disorders of acute and chronic pain often co-occur with AUDs, with chronic pain affecting an estimated 114 million adult Americans [3, 4]. Alcohol has analgesic properties, with $38 \%$ of heavy drinkers reportedly drinking to treat pain [5]. Drinking to cope with physical pain can be effective initially due to the analgesic properties of alcohol [6]. However, the analgesic effects of alcohol are brief and dosedependent, with tolerance emerging relatively quickly $[6,7]$. These pharmacological properties of alcohol can lead to physiological dependence on alcohol for pain relief, contributing to negative reinforcement driven alcohol use [3, 8]. Importantly, neurotoxic effects of alcohol can result in alcoholic neuropathy after chronic use. Furthermore, alcohol withdrawal is associated with the emergence of hyperalgesia [9-13] and allodynia which can persist after weeks or months of abstinence [10]. Moreover, this effect is seen in patients who are alcohol dependent but report no preexisting chronic or acute pain conditions. For example, pain-free patients may develop a new heightened sensitivity to painful stimuli when they undergo withdrawal from alcohol after prolonged use $[3,10]$. This effect has been well documented in preclinical studies where alcohol withdrawal-induced hyperalgesia is extensively reported in rodents [14-32].

Major barriers to achieving abstinence and preventing relapse include the emergence of negative affect and increased pain sensitivity during alcohol withdrawal [3, 33]. Effective pharmacological treatments targeting the interdependence between alcohol and pain are currently limited. For example, Gabapentin is used to treat both acute [34-39] and chronic pain conditions [40-45], and has recently emerged as a possible pharmacotherapeutic for AUDs [46-52]. The Federal Drug Administration has approved the drugs disulfiram, acamprosate, and naltrexone to 
treat AUDs; however, clinical data indicate these medications are only partially effective and have high rates of relapse upon discontinuation of the drugs [53]. None of the medications approved to treat AUDs are useful for treatment of pain associated with alcohol withdrawal. These data underscore the high need to identify new potential therapeutic approaches for the treatment of alcohol withdrawal associated hyperalgesia, which could facilitate abstinence by reducing negative reinforcement driven alcohol use in treatment-seeking individuals.

One emerging target for the treatment of pain is the endogenous cannabinoid (eCB) system, which acts throughout neural nociceptive system to produce antinociceptive and analgesic effects $[54,55]$. The eCBs 2-Arachidonoylglycerol (2-AG) and N-arachidonoylethanolamine (AEA) exert antinociceptive effects in rodents through activation of $\mathrm{CB} 1$ and $\mathrm{CB} 2$ receptors [56]. These eCBs are also implicated in setting nociceptive thresholds and regulating tonic inhibition of pain responses [56, 57]. Pharmacological inhibition of the major 2-AG catabolic enzyme monoacylglycerol lipase (MAGL) results in increased brain and peripheral levels of 2-AG and exerts analgesic and anti-allodynic effects of in a variety of preclinical models via CB1 and CB2 receptor $[58-66]$.

Here we utilized a continuous access two bottle choice alcohol drinking paradigm combined with pharmacological approaches to test the hypothesis that 2-AG signaling regulates pain sensitivity during alcohol withdrawal. We report that pharmacological augmentation of 2AG during alcohol withdrawal reverses mechanical hypersensitivity associated with alcohol withdrawal in mice via actions at both $\mathrm{CB} 1$ and $\mathrm{CB} 2$ receptors. Conversely, pharmacological 2AG depletion worsens and extends the time course of hyperalgesia observed during alcohol withdrawal, suggesting a critical role for endogenous 2-AG to counteract hyperalgesia during withdrawal. These data provide new insight into the mechanisms underlying alcohol withdrawal 
associated hyperalgesia and suggest 2-AG augmentation could represent a novel treatment approach of AUD in patients with comorbid pain disorders.

\section{METHODS AND MATERIALS}

\section{Animals}

C57BL/6J (Jackson Laboratory, ME) female and male mice were between 6-7 weeks old at the beginning of experiments. The animal care facilities at Vanderbilt University (Nashville, TN), housed mice in climate-controlled colony rooms, maintained at $21 \pm 2{ }^{\circ} \mathrm{C}, 30 \% \pm 10 \%$ relative humidity on a 12L:12D cycle, with lights on at $0600 \mathrm{~h}$. Food and water were provided ad libitum (LabDiet 5001; LabDiet) for the duration of the experiments. All behavior experiments were conducted during the light phase. All studies were carried out in accordance with the National Institute of Health Guide for the Care and Use of Laboratory Animals and approved by the Vanderbilt University Institutional Animal Care and Use Committee (\#M1600213-01).

\section{Drugs}

The MAGL inhibitor JZL184 (10 mg/kg-1 , Cayman Chemical, MI, USA), CB ${ }_{1}$ R inverse agonist Rimonabant (3 mg kg-1 APIChem, Hangzhou, Zhejiang, China), and $\mathrm{CB}_{2} \mathrm{R}$ inverse agonist AM630 (3 mg kg-1 Cayman Chemical, MI, USA) were prepared in DMSO and injected i.p.at $1 \mu \mathrm{g} \mathrm{g}^{-1}$ bodyweight. DAGL inhibitor DO34 (50 $\mathrm{mg} \mathrm{kg}^{-1}$, Glixx Laboratories Inc., MA) was administered in a vehicle mixture of ethanol (Pharmco, KY, USA): kolliphor (Sigma-Aldrich, WI,): saline (Hospira, IL, USA) [1:1:18] was injected at a volume of $10 \mu \mathrm{lg}^{-1}$ bodyweight. All drugs were administered 2 hours before behavior testing. 190 proof ACS/USP grade grain-derived EtOH (Pharmco, KY, USA) was used to for EtOH drinking solutions. 


\section{Two-bottle choice EtOH drinking and withdrawal model}

Mice were first acclimated to single-housed two-bottle choice (2BC) cages for 7 days, with two sippers and access to tap water only. For EtOH mice, one bottle of tap water was replaced with $3 \% \mathrm{EtOH}$ in tap water for 4 days. On the $5^{\text {th }}$ day, the EtOH concentration increased to $7 \%$ for 7 days. On the $8^{\text {th }}$ day, the EtOH bottle concentration increased to $10 \%$ or $20 \%$ and were continues at this concentration until testing or forced abstinence. EtOH bottle placement (left or right sipper) was rotated weekly. For withdrawal tests, after 21 days of drinking in $2 \mathrm{BC}$ cages with either one bottle of $10 \%$ or $20 \% \mathrm{EtOH}$, the $\mathrm{EtOH}$ bottle was replaced with tap water. Control mice were housed in the same conditions for the duration of the experiment with two bottles of tap water. Mice undergoing EtOH withdrawal were kept physically separated from control mice in the facility to prevent social transfer of pain sensitivity, by use of adjoining enclosed housing rooms [19].

\section{Pain Assays}

Mechanical punctate sensitivity was assessed by manual application of Von Frey filaments of varying forces (0.4-4.0g) using the "ascending stimulus" method [67]. Mice were tested in groups of four in a plexiglass testing rack, which had 4 clear plexiglass experimental cubbies boxes. Because mice were single housed for a protracted period, the interior walls of each cubby were covered with a thin piece of dark plastic, so the mice could not see each other during habituation and testing. Each mouse had left hind paw tested first, with increasing grams force monofilaments applied until a positive response was observed. 'Positive response' included of paw withdrawal, paw licking, or shaking, either during application or immediately after the filament was removed. The grams force of the von Frey filament that elicited a positive response was designated as the mechanical withdrawal threshold for that trial. The trial was repeated once again for the left hind 
paw, with monofilaments applied in ascending grams force until a positive response. Next, the second mouse on the apparatus was tested for two trials on left hind paw, followed by third mouse in the apparatus and the fourth. Then, the same two-trial procedure was repeated for each mouse using the plantar surface of each right paw. Averaged paw withdrawal thresholds are reported [68] Thermal sensitivity was assessed with the hot plate test, performed as previously described [69], with mice placed onto a flat surface pre-heated to $50^{\circ} \mathrm{C}$ within an open Plexiglas tube. Latency to the first positive response was recorded, with a cutoff time of 40 seconds. Positive responses included hind paw shaking or hind paw licking, or mouse jumping. Latency in seconds to positive response or reaching cutoff time with no positive responses for one trial per mouse is reported.

\section{Irritability-like behavior tests}

To measure “irritability”, we used the Bottle Brush Test for mice [70-72]. After 30 minutes of acclimation to the testing room, mice were placed alone in their open home cage. Two cameras were aimed at the clear cage, one from a lateral side view and one overhead. The experimenter used a bottle brush - a small white plastic brushed with a rounded top of protruding plastic bristles, used to clean small bottles. Briefly, mice were lightly "attacked" by the brush (touched by the bristles of the brush and followed around by the brush) in the following sequence:

(1) Brush (in rotation) approaching the mouse from the end (starting position) of the cage.

(2) Brush (in rotation) touching the whiskers of the mouse.

(3) Brush (in rotation) returning to the starting position in the opposite end of the

(4) Brush (in rotation) at the starting position.

(5) Brush (no rotation) at the starting position. 
Each mouse was attacked by the bottle brush 20 times per session. Videos were coded using ANVIL video coding software [73] for the following positive responses: (1) mouse was climbing cage wall during the bottle brush attack, (2) digging, (3) running away/escaping the bottle brush, (4) freezing in response to the bottle brush attack, or (5) exploring the bottle brush as it was touching them. Using the ANVIL time coding function, the during of each positive response was recorded. The total time for each positive response during 20 bottle brush attacks is reported for each mouse.

\section{Anxiety-like behavior tests}

Elevated Plus Maze (EPM), Open Field Test (OFT) and Light-Dark Box (LD) were performed exactly as previously described [74].

The EPM had two wall-free open-arms $(30 \times 10 \mathrm{~cm}$; light illuminance $\sim 100-115$ lux $)$, and 2 walled ("closed") arms $(30 \times 10 \times 15 \mathrm{~cm} ; \sim 20-25 \mathrm{lux})$ anchored to a square $5 \times 5 \mathrm{~cm}$ open center. To begin the test and trigger video tracking, mice were placed in the center, facing an open arm. Maze was made of white acrylonitrile butadiene styrene plastic and elevated $47 \mathrm{~cm}$ off the ground. Each mouse explored the EPM for 5 minutes per test, with ANY-maze (Stoelting, Wood Dale, Illinois) video tracking software used to monitor and analyze behavior during testing.

The OFT used a square sound-attenuating chamber with clear plexiglass walls $(27.9 \times 27.9$ × $20.3 \mathrm{~cm}$; MED-OFA-510; MED Associates, St. Albans, Vermont) contained within a white sound-attenuating chamber box. Mice were placed in the center of the open field chamber to begin the test and recorded for 5 minutes, with beam breaks from 16 infrared light beams measuring movement and position with Activity Monitor v5.10 (MED Associates) software. The center of the OFT was designated as a square of the innermost $50 \%$ of the OFT arena floor, with the 
remainder considered the perimeter. The chamber was illuminated at 200 lux and white noise was present at $\sim 60 \mathrm{~dB}$.

The LD box test used a black insert (Med Associates ENV-511; made of IRT to allow infrared beam transmission) was placed into a chamber with clear plexiglass walls $(27.9 \times 27.9 \times$ $20.3 \mathrm{~cm}$; MED-OFA-510) to split the chamber into equal halves light $(\sim 350-400$ lux $)$ and dark $(<5$ lux) divisions. Beam breaks from 16 infrared beams were recorded Activity Monitor v5.10 (MED Associates) to monitor position and behavior during the 10-min test. White noise was present at $\sim 60 \mathrm{~dB}$.

\section{RESULTS}

\section{Hyperalgesia during EtOH withdrawal}

We first investigated the effects of withdrawal from $10 \% \mathrm{EtOH}$ on nocifensive behaviors (Fig.1). Mechanical and thermal sensitivity were measured 24 hours, 72 hours, and one week into withdrawal (Fig.1A). Compared to water drinking controls, EtOH withdrawal mice showed increased mechanical hypersensitivity, with significantly lower paw withdrawal thresholds on the Von Frey filament test at 72 hours into withdrawal. However, no significant effect of EtOH withdrawal was seen at the earlier withdrawal timepoint of 24 hours, or at the late timepoint of one-week post EtOH withdrawal (Fig.1B). In contrast, there was no difference between alcohol withdrawal and water-drinking controls on the hot plate test of thermal sensitivity at any time point (Fig.1C). A separate cohort of mice were tested on the Von Frey filament and hot plate tests after three weeks stable drinking on $10 \% \mathrm{EtOH}$ in $2 \mathrm{BC}$, i.e. not in withdrawal (Fig. 1D). Mice drinking $10 \% \mathrm{EtOH}$ in $2 \mathrm{BC}$ were not different from water controls on either Von Frey (Fig. 1E) or hot plate (Fig. 1F) thresholds. These data indicate that alcohol withdrawal is associated with a timed- 
dependent emergence of mechanical, but not thermal, hypersensitivity, and that this effect is not observed during alcohol drinking per se, and thus selective to the withdrawal state.

\section{JZL184 reverses mechanical hypersensitivity associated with EtOH withdrawal}

We next conducted several independent experiments to determine if pharmacologically increasing 2-AG levels affected the increased mechanical hypersensitivity observed during EtOH withdrawal. First, baseline Von Frey threshold was determined (Fig. 2A) prior to initiation of the 2BC model. After ramping up from 3\%-10\% EtOH, mice drank $10 \% \mathrm{EtOH}$ for three weeks, and were tested using the Von Frey assay at 72 hours into withdrawal (Fig. 2A). EtOH withdrawn mice treated with vehicle had significantly reduced Von Frey thresholds compared to their own baselines whereas no changes in Von Frey threshold were detected in water control mice across these time points. (Fig. 2C). Beginning immediately after $72 \mathrm{hr}$ withdrawal Von Frey testing was completed, the $\mathrm{EtOH}$ mice were placed back on $2 \mathrm{BC} 10 \% \mathrm{EtOH}$ for two additional weeks. After two weeks of additional drinking, EtOH was again removed for mechanical sensitivity testing at 72 hours withdrawal. This time, water mice and EtOH mice were pretreated with MAGL inhibitor JZL184 (10 $\left.\mathrm{mg} \mathrm{kg}^{-1}\right)$ to determine if increasing 2-AG levels could reverse hyperalgesia at 72 hours of EtOH withdrawal, and if JZL184 has analgesic properties in control mice drinking water only (Fig. 2A). JZL184 normalized mechanical hypersensitivity by significantly increasing Von Frey threshold in mice in EtOH withdrawal (Fig. 2B-C). The water-only group tested alongside the withdrawal mice showed no differences when tested at baseline, with vehicle, or with JZL184 pretreatment.

To confirm these findings using a between-subjects design, a separate cohort of 2BC EtOH drinking mice were treated with vehicle or JZL184 (10 $\left.\mathrm{mg} \mathrm{kg}^{-1}\right)$ and tested at 72 hours withdrawal 
from $10 \% \mathrm{EtOH}$ (Fig. 2D). Consistent with previous experiment, JZL184 was able to significantly increase Von Frey thresholds relative to vehicle treatment at $72 \mathrm{~h}$ into EtOH withdrawal (Fig. 2EF). Immediately after Von Frey testing with vehicle or JZL184 pretreatment during $72 \mathrm{~h}$ of withdrawal from $10 \% \mathrm{EtOH}$, mice were put back into $2 \mathrm{BC}$ cages and given one bottle of water and one bottle of $20 \% \mathrm{EtOH}$. After two weeks of drinking, access to $20 \% \mathrm{EtOH}$ was removed, and Von Frey testing was gain conducted at $72 \mathrm{~h}$ into withdrawal (Fig. 2D). Again, 72 hours after access to $20 \% \mathrm{EtOH}$ was removed, mechanical hypersensitivity was seen in vehicle treated mice (Fig. $2 \mathrm{G})$. There were no differences in the hyperalgesia triggered by removal of access from $20 \% \mathrm{EtOH}$

(Fig. 2G) when compared to mechanical hypersensitivity seen 72 hours after removal of access from 10\% EtOH (Fig. 2F, Fig. 2C, and Fig. 1C). Again, confirming out previous experiment, JZL184 was also able to reverse mechanical hypersensitivity $72 \mathrm{~h}$ into withdrawal from $20 \% \mathrm{EtOH}$ (Fig. 2G). These data provide compelling evidence that MAGL inhibition can reduce mechanical hypersensitivity induced by alcohol withdrawal.

\section{Hyperalgesia during EtOH withdrawal does not depend on concurrent increases in anxiety-}

\section{like behavior}

We considered the possibility that EtOH withdrawal-induced hyperalgesia could be considered one effect among several seen in the broader context of a general aversive behavioral response to alcohol withdrawal. To determine if mechanical hypersensitivity was an independent effect of EtOH withdrawal or was contingent upon an increase in anxiety-like behavior, the open field test was done during 72-hour withdrawal with a new cohort of $10 \% \mathrm{EtOH}$ drinking mice. The $\mathrm{EtOH}$ withdrawal mice were no different in the total or center distance travelled in the open field test but spent more time in the center of the apparatus than water-drinking controls (Fig. 3). After 
this, the light-dark box and elevated-plus maze tests were conducted after mice were put back on EtOH for two weeks to achieve stable drinking levels, then EtOH was removed for 72 hours (Fig. 3A). Mice in EtOH withdrawal did not exhibit increase anxiety-like behavior on any measure. The lack of differences between groups indicates the mechanical hypersensitivity see in EtOH withdrawal groups is not associated with increases in anxiety-like behaviors at the 72 hour timepoint.

EtOH withdrawal induces irritability behavior, which is not prevented with MAGL inhibition

In the next experiment, mice in $\mathrm{EtOH}$ withdrawal were tested to determine if they expressed concurrent states of irritability-like behavior during EtOH withdrawal. Compared to water-only controls, EtOH withdrawal mice engaged in fleeing, but not digging, behavior significantly more often in the bottle brush irritability test (Fig. 4A). Furthermore, treatment with JZL-184 (10 $\left.\mathrm{mg} \mathrm{kg}^{-1}\right)$ was not able to prevent increases in irritability behavior in a separate cohort of EtOH drinking mice in 72-hour withdrawal (Fig. 4B). EtOH withdrawal thus results in irritability and mechanical hypersensitivity. This lack of sensitivity to JZL184 suggests the neural mechanisms underlying mechanical hypersensitivity triggered by EtOH withdrawal and irritability-like behaviors are likely dissociable.

\section{Both CB1 and CB2 receptor antagonists prevent the anti-hyperalgesic effects of MAGL inhibition}

Because JZL184 reverses mechanical hypersensitivity during EtOH withdrawal, we next sought to further characterize the pharmacological mechanisms underlying these effects. To 
determine if the anti-hyperalgesic properties of 2-AG are mediated through $\mathrm{CB} 1$ or $\mathrm{CB} 2$ receptors, mice underwent 72 hours of EtOH withdrawal and were treated with JZL184 alone, or JZL184 in combination with $\mathrm{CB}_{1} \mathrm{R}$ and $\mathrm{CB}_{2} \mathrm{R}$ antagonists (Fig. 5). Mechanical hypersensitivity returned when JZL184 was co-administered with either the $\mathrm{CB}_{1} \mathrm{R}$ antagonist Rimonabant $\left(3 \mathrm{mg} \mathrm{kg}^{-1}\right)$, or the $\mathrm{CB}_{2} \mathrm{R}$ antagonist AM-630 (3mg kg-1). The antinociceptive effect of JZL184 was completely blocked by both $\mathrm{CB}$ receptor antagonists (Fig. 5A). No differences in Von Frey threshold were seen in control mice that only drank water and were treated with Rimonabant $\left(3 \mathrm{mg} \mathrm{kg}^{-1}\right)$, or AM$630\left(3 \mathrm{mg} \mathrm{kg}^{-1}\right)$, two hours before the Von Frey testing (Fig. 5B). This implies the involvement of $\mathrm{CB}_{1}$ and $\mathrm{CB}_{2}$ receptors in the anti-hyperalgesic effects of JZL184.

\section{The DAGL inhibitor DO34 enhanced mechanical hypersensitivity during EtOH withdrawal}

The lowered mechanical sensitivity threshold triggered by $72 \mathrm{EtOH}$ withdrawal was prevented with a MAGL inhibitor, and this effect was blocked by both $\mathrm{CB}_{1} \mathrm{R}$ and $\mathrm{CB}_{2} \mathrm{R}$ antagonists. To further characterize the specific role of 2-AG signaling in the regulation of mechanical hypersensitivity during EtOH withdrawal, the DAGL inhibitor DO34 was used to block the endogenous synthesis of 2-AG (Fig. 6A). After 3 weeks $2 \mathrm{BC}$ drinking, EtOH bottles were removed and the Von Frey testing was completed after 24 hours, 72 hours, and one week of withdrawal. DO34 pretreatment led to a robust emergence of previously unseen mechanical hypersensitivity at 24 hours withdrawal, with significantly lowered Von Frey thresholds (Fig. 6B). Next, as predicted, the mechanical thresholds of both vehicle and DO34 groups was very low on the Von Frey test at 72 hours withdrawal. Finally, DO34 completely prevented recovery of normal mechanical responses, and caused persistent withdrawal-triggered hypersensitivity at one-week into EtOH withdrawal (Fig. 6B-C). Alcohol consumption and preference for this cohort of mice is 
shown in Fig. 6D-E. Lastly, we showed that DO34 did not affect mechanical sensitivity thresholds in water drinking mice (Fig. 6F). These data indicate that inhibition of DAGL leads to an earlier onset and persistent mechanical hypersensitivity induced by EtOH withdrawal, and that the effects of 2-AG depletion are specific to the alcohol withdrawal state as DO34 has no effect on sensitivity thresholds in control mice.

\section{DISCUSSION}

Here we show that pharmacological inhibition of MAGL prevents alcohol withdrawalinduced mechanical hypersensitivity via activation of $\mathrm{CB}_{1}$ and $\mathrm{CB}_{2}$ receptors. Importantly, neither 2-AG augmentation nor 2-AG inhibition affected mechanical sensitivity thresholds in water drinking mice or in mice exposed to alcohol but not in withdrawal. These data are partially consistent with recent data indicating MAGL inhibition within the lateral habenula reduces mechanical hypersensitivity rats undergoing alcohol withdrawal; however, in this study MAGL inhibition also increased mechanical thresholds to a similar degree in control rats [20]. We also showed that endogenous 2-AG serves to counteract alcohol withdrawal associated mechanical hypersensitivity, as blockade of 2-AG synthesis accelerated the onset and dramatically extended the time course of hyperalgesia in our model. That blockade of 2-AG synthesis had no effect on mechanical sensitivity thresholds in control mice suggests alcohol withdrawal is associated with an adapted state during which endogenous $2-A G$ exerts analgesic effects to limit the adverse consequences of withdrawal on pain sensitivity. These data demonstrate a critical role for 2-AG in the bidirectional modulation of mechanical sensitivity thresholds selectively during alcohol withdrawal and suggest MAGL inhibition could represent a novel approach to the treatment of hyperalgesic states associated with alcohol withdrawal. 
MAGL inhibition has been shown to reduce neuropathic pain [75], pain induced by trigeminal nerve injury [76], chemotherapy-induced neuropathic pain [77], pain induced by models of multiple sclerosis [59], pain arising from inflammatory states [60], joint pain in osteoarthritis models [78], and chronic stress-induced hyperalgesia [79]. Previous studies have also implicated $\mathrm{CB}_{1}$ and $\mathrm{CB}_{2}$ receptors in the analgesic effects of MAGL inhibition in various preclinical models $[58,66,75,77]$. Our data and a recent study [20] confirm the preclinical efficacy of MAGL inhibition in the reduction of mechanical hypersensitivity associated with alcohol withdrawal. There is some evidence that MAGL inhibition can increase hedonic behavior [80, 81], however we have previously shown that MAGL inhibition did not increase alcohol consumption or preference in mice [82], and direct lateral habenula MAGL inhibition actually reduced operant alcohol self-administration [20]. Moreover, MAGL inhibition has been shown to reduce negative affective states induced by alcohol withdrawal [83]. These findings, combined with our present results suggest MAGL inhibition could represent an important new approach to reduce negative reinforcement driven alcohol use by reducing both negative affective and somatic states associated with alcohol withdrawal without propensity to increase alcohol intake per se.

Augmentation of 2-AG levels via pharmacological MAGL inhibition has been shown to act on both $\mathrm{CB}_{1}$ and $\mathrm{CB}_{2}$ receptors to reduce pain sensitivity $[58,66,75,77,84]$. In the brain, the $\mathrm{CB}_{1}$ receptor is the most dominant eCB binding site $[85,86]$, while the $\mathrm{CB}_{2}$ receptor is largely associated with immune cells and microglia in the CNS [86-89]. Our pharmacological studies demonstrate that blockade of either $\mathrm{CB}_{1}$ receptors with Rimonabant or $\mathrm{CB}_{2}$ receptors with $\mathrm{AM} 630$ both prevent the anti-hyperalgesic effects of JZL184. These data indicate JZL184 given during alcohol withdrawal reduces mechanical hypersensitivity through activation of both $\mathrm{CB}_{1}$ and $\mathrm{CB}_{2}$ receptors, consistent with a dual receptor mechanism in a variety of other models noted above. The 
relative contribution of central vs. peripheral cannabinoid receptors to the anti-hyperalgesic effects of JZL184 during alcohol withdrawal is not known but is an important area for future investigation that could have important implications for 2-AG-based therapeutics development.

The present studies also support the critical role of endogenous 2-AG signaling in pain processing during alcohol withdrawal. Postsynaptic 2-AG is synthesized on-demand by the enzyme DAGL $\alpha$ in neurons [90-92]. Pharmacological inhibition of DAGL via the compound DO34 results in dramatic decreases in brain 2-AG levels $[82,93]$. DAGL $\alpha^{-1-}$ mice exhibit more anxiety-like and depression-like behaviors at baseline [94, 95], and DO34 treatment after acute stress causes increased anxiety and depression-like behaviors [96]. Our lab has also shown DO34 impairs fear extinction in mice [97], and reduces alcohol consumption in a two-bottle choice paradigm [82]. However, little is known about the effects of inhibition of DAGL on pain processing. The current studies demonstrate that blocking synthesis of 2-AG exacerbates pain sensitivity, causing an earlier onset of mechanical hypersensitivity during withdrawal (24 hours), which persisted beyond the recovery time established in the previous experiments. Under the current experimental conditions, mice treated with DO34 demonstrated robust mechanical hypersensitivity that persisted 7 days into alcohol withdrawal. The current results are difficult to directly compare to previous findings, with one published study by Wilkerson and colleagues indicating pain sensitivity was reduced by DO34 in a model of LPS-induced allodynia [98]. However, this could be due in part to an anti-inflammatory effects secondary to reduced production of 2-AG-derived pro-inflammatory prostaglandins. We have shown previously that 2-AG derived proinflammatory prostaglandin glycerol esters (PG-Gs) can be generated following LPS-driven upregulation of cyclooxygenase-2 [99], and several other reports have shown LPS increases the production of pro-inflammatory prostaglandins [100-102]. In support of our current findings of 
reduced mechanical sensitivity thresholds in alcohol withdrawal after DO34 treatment, another study demonstrated that pharmacological inhibition of DAGL reduced orbital, but not hind paw, mechanical sensitivity thresholds [103]. Future studies will be needed to determine the specific conditions under which 2-AG signaling represents an anti-hyperalgesic system.

Previous studies have implicated $\mathrm{CB}_{1}$ receptors in the suppression of nociceptive transmission [104-108]. For example, Rimonabant administration results in hyperalgesia in the formalin paw test $[109,110]$ and hot plate test [111], and reverses stress induced analgesia [112]. Taken together, these data suggest alcohol withdrawal recruits 2-AG signaling to counteract mechanical hypersensitivity over extended time scales (at least $\sim 1$ week). Future studies aimed at elucidating the receptor mechanisms subserving this adaptive process would be of high significance and may reveal mechanistic insight into how 2-AG signaling regulates nociceptive processing as a function of alcohol withdrawal states.

We have previously shown that alcohol withdrawal increases negative affective states during protracted withdrawal in mice, some of which can be reversed by MAGL inhibition [113]. However, we did not detect clear changes in anxiety-like behaviors at the $72 \mathrm{~h}$ time point in any assay we conducted, suggesting that the increase in mechanical sensitivity was not secondary to increases in anxiety-like states of mice. In contrast to our findings, mice treated with alcohol five consecutive days a week for 3-4 weeks via oral gavage exhibited both anxiety-like behavior and mechanical allodynia at 24 hours of alcohol withdrawal $[15,114]$. However, this could be partially due to increased stress response seen with oral gavage methods $[115,116]$. Others have reported the emergence of anxiety-like behaviors at different withdrawal time points, such as 5-50 hours into withdrawal, many using alcohol vapor exposure [117-127]. The findings are not easily compared between studies using different routes of administration and time of testing in 
withdrawal. Overall, the data presented here agree with literature showing three days as the optimal withdrawal time for induction hyperalgesia in mice following chronic alcohol drinking in a twobottle choice model [128, 129]. Under the current experimental conditions of 72-hour withdrawal from alcohol, the effects on mechanical sensitivity and anxiety-like behaviors appear dissociable.

In clinical literature, irritability is one of three conditions contributing to a negative emotional states during drug withdrawal (dysphoria, anxiety, and irritability) [130, 131] and contributing to relapse [132]. Irritability-like behavior is challenging to model in rodents, with early alcohol withdrawal experiments relying on subjective experimenter observations of "irritability" in rodents [133-136]. The bottle brush test used here is a measure of irritability in rodents based on a tactile stimulus, which has been shown to detected the presence of irritabilitylike behavior during alcohol withdrawal [137] and oxycodone withdrawal [138]. It is possible that the decreased withdrawal thresholds (increased mechanical sensitivity) measured by the Von Frey tests could be related to irritability rather than hyperalgesia per se. Indeed, we did detect increases in irritability-like behavior at $72 \mathrm{~h}$ of withdrawal, however, this effect was not reversed by JZL184 treatment. These data suggest that reduced withdrawal thresholds observed using the Von Frey test were not likely secondary to changes in irritability, since they were robustly reversed by JZL184, whereas irritability-like behaviors were not affected by JZL184.

While the current set of experiments focus on the eCB 2-AG, future work should determine how the eCB anandamide (AEA) may influence pain or hypersensitivity during alcohol withdrawal. Inhibition of fatty acid amide hydrolase (FAAH), the primary AEA degrading enzyme, abolished alcohol withdrawal anxiety seen following a single alcohol IP injection [139], and $\mathrm{FAAH}^{-/-}$mice are less susceptible to handling-induced convulsions following chronic ethanol exposure [140]. Furthermore, FAAH inhibition reportedly reduced allodynia when co- 
administered with a COX-2 inhibitor in models of neuropathy and inflammation [141], and FAAH inhibitor URB597 was analgesic in both control and ethanol withdrawal mice when injected into the lateral habenula [20]. Finally, in addition to MAGL, the ABHD6 enzyme hydrolyzes 2-AG in the brain and is located on postsynaptic neuronal elements [142]. The literature on the role of this enzyme in pain processing is limited, but there is some evidence inhibition of ABHD6 is antinociceptive in neuropathic pain models [143], and may regulate production of 2-AG derived pro-inflammatory prostaglandins [144]. Future studies examining these approaches would be important.

In summary, the present experiments provide insight into the regulatory role of 2-AG signaling in mechanical hypersensitivity during alcohol withdrawal. Inhibition of MAGL reduced mechanical hypersensitivity during alcohol withdrawal, while blocking 2-AG synthesis caused an earlier induction of hypersensitivity during withdrawal, and prevented recovery, with effects persisting up to 7 days into withdrawal. These data provide insight into the therapeutic potential of MAGL inhibitors in AUD.

\section{ACKNOWLEDGEMENTS}

These studies were supported by NIH grants AA026186 (S.P.). The content is solely the responsibility of the authors and does not necessarily represent the official views of the National Institutes of Health.

\section{DISCLOSURES}

S.P. is a scientific consultant for Psy Therapeutics and Jazz Pharmaceuticals. 


\section{REFERENCES}

1. Grant, B.F., et al., Epidemiology of DSM-5 Alcohol Use Disorder: Results From the National Epidemiologic Survey on Alcohol and Related Conditions III. JAMA Psychiatry, 2015. 72(8): p. 757-66.

2. Administration., S.A.a.M.H.S., Key substance use and mental health indicators in the United States: Results from the 2020 National Survey on Drug Use and Health. 2021, Center for Behavioral Health Statistics and Quality, Substance Abuse and Mental Health Services Administration: Rockville, MD.

3. Egli, M., G.F. Koob, and S. Edwards, Alcohol dependence as a chronic pain disorder. Neurosci Biobehav Rev, 2012. 36(10): p. 2179-92.

4. Grant, B.F., et al., Prevalence and co-occurrence of substance use disorders and independent mood and anxiety disorders: results from the National Epidemiologic Survey on Alcohol and Related Conditions. Arch Gen Psychiatry, 2004. 61(8): p. 807-16.

5. Alford, D.P., et al., Primary Care Patients with Drug Use Report Chronic Pain and SelfMedicate with Alcohol and Other Drugs. J Gen Intern Med, 2016. 31(5): p. 486-91.

6. Thompson, T., et al., Analgesic Effects of Alcohol: A Systematic Review and MetaAnalysis of Controlled Experimental Studies in Healthy Participants. J Pain, 2017. 18(5): p. 499-510.

7. Maleki, N., et al., At the intersection of alcohol use disorder and chronic pain. Neuropsychology, 2019. 33(6): p. 795-807.

8. Apkarian, A.V., et al., Neural mechanisms of pain and alcohol dependence. Pharmacol Biochem Behav, 2013. 112: p. 34-41.

9. Edwards, S., et al., Alcohol and Pain: A Translational Review of Preclinical and Clinical Findings to Inform Future Treatment Strategies. Alcohol Clin Exp Res, 2020. 44(2): p. 368-383.

10. Jochum, T., et al., Increased pain sensitivity in alcohol withdrawal syndrome. Eur J Pain, 2010. 14(7): p. 713-8.

11. You, D.S., et al., Hyperalgesia after a Drinking Episode in Young Adult Binge Drinkers: $A$ Cross-Sectional Study. Alcohol Alcohol, 2020. 55(6): p. 608-615.

12. Kopera, M., et al., Pain Sensitivity, Negative Affect, and Alcohol Use Disorder Status: A Moderated Mediation Study of Emotion Dysregulation. J Clin Med, 2021. 10(6).

13. Jakubczyk, A., et al., The synergistic effect between interoceptive accuracy and alcohol use disorder status on pain sensitivity. Addict Behav, 2021. 112: p. 106607.

14. Pradhan, A.A., et al., Effect of Histone Deacetylase Inhibitor on Ethanol WithdrawalInduced Hyperalgesia in Rats. Int J Neuropsychopharmacol, 2019. 22(8): p. 523-527.

15. Alongkronrusmee, D., T. Chiang, and R.M. van Rijn, Involvement of delta opioid receptors in alcohol withdrawal-induced mechanical allodynia in male C57BL/6 mice. Drug Alcohol Depend, 2016. 167: p. 190-8.

16. Avegno, E.M., et al., Central Amygdala Circuits Mediate Hyperalgesia in AlcoholDependent Rats. J Neurosci, 2018. 38(36): p. 7761-7773.

17. Gatch, M.B., Effects of benzodiazepines on acute and chronic ethanol-induced nociception in rats. Alcohol Clin Exp Res, 1999. 23(11): p. 1736-43. 
18. Dina, O.A., R.O. Messing, and J.D. Levine, Ethanol withdrawal induces hyperalgesia mediated by PKCepsilon. Eur J Neurosci, 2006. 24(1): p. 197-204.

19. Smith, M.L., et al., Social transfer of pain in mice. Sci Adv, 2016. 2(10): p. e1600855.

20. Fu, R., et al., Endocannabinoid signaling in the lateral habenula regulates pain and alcohol consumption. Transl Psychiatry, 2021. 11(1): p. 220.

21. Gatch, M.B. and H. Lal, Effects of ethanol and ethanol withdrawal on nociception in rats. Alcohol Clin Exp Res, 1999. 23(2): p. 328-33.

22. Gatch, M.B. and M. Selvig, Theophylline blocks ethanol withdrawal-induced hyperalgesia. Alcohol Alcohol, 2002. 37(4): p. 313-7.

23. Gatch, M.B., Ethanol withdrawal and hyperalgesia. Curr Drug Abuse Rev, 2009. 2(1): p. 41-50.

24. Gilpin, N.W., W. Yu, and T.L. Kash, Forebrain-Midbrain Circuits and Peptides Involved in Hyperalgesia After Chronic Alcohol Exposure. Alcohol Res, 2021. 41(1): p. 13.

25. Kang, S., et al., Downregulation of M-channels in lateral habenula mediates hyperalgesia during alcohol withdrawal in rats. Sci Rep, 2019. 9(1): p. 2714.

26. Kononoff, J., et al., Systemic and Intra-Habenular Activation of the Orphan G ProteinCoupled Receptor GPR139 Decreases Compulsive-Like Alcohol Drinking and Hyperalgesia in Alcohol-Dependent Rats. eNeuro, 2018. 5(3).

27. Li, J., et al., Electroacupuncture Attenuates Hyperalgesia in Rats Withdrawn from Chronic Alcohol Drinking via Habenular Mu Opioid Receptors. Alcohol Clin Exp Res, 2017. 41(3): p. 637-643.

28. Quadir, S.G., et al., The Sigma-2 receptor / transmembrane protein 97 ( $\sigma 2 R / T M E M 97)$ modulator JVW-1034 reduces heavy alcohol drinking and associated pain states in male mice. Neuropharmacology, 2021. 184: p. 108409.

29. Roltsch Hellard, E.A., R.A. Impastato, and N.W. Gilpin, Intra-cerebral and intra-nasal melanocortin-4 receptor antagonist blocks withdrawal hyperalgesia in alcoholdependent rats. Addict Biol, 2017. 22(3): p. 692-701.

30. Shumilla, J.A., et al., Ethanol withdrawal-associated allodynia and hyperalgesia: agedependent regulation by protein kinase C epsilon and gamma isoenzymes. J Pain, 2005. 6(8): p. 535-49.

31. Urtado, M.B., et al., Involvement of peripheral TRPV1 in TMJ hyperalgesia induced by ethanol withdrawal. Life Sci, 2007. 81(23-24): p. 1622-6.

32. Walcott, A.T., et al., Social transfer of alcohol withdrawal-induced hyperalgesia in female prairie voles. Soc Neurosci, 2018. 13(6): p. 710-717.

33. Heilig, M., et al., Acute withdrawal, protracted abstinence and negative affect in alcoholism: are they linked? Addict Biol, 2010. 15(2): p. 169-84.

34. Doleman, B., et al., A systematic review and meta-regression analysis of prophylactic gabapentin for postoperative pain. Anaesthesia, 2015. 70(10): p. 1186-204.

35. Ho, K.Y., T.J. Gan, and A.S. Habib, Gabapentin and postoperative pain--a systematic review of randomized controlled trials. Pain, 2006. 126(1-3): p. 91-101.

36. Yan, P.Z., et al., Beyond neuropathic pain: gabapentin use in cancer pain and perioperative pain. Clin J Pain, 2014. 30(7): p. 613-29. 
37. Zude, B.P., K. Jampachaisri, and C. Pacharinsak, Use of Flavored Tablets of Gabapentin and Carprofen to Attenuate Postoperative Hypersensitivity in an Incisional Pain Model in Rats (J Am Assoc Lab Anim Sci, 2020. 59(2): p. 163-169.

38. Dauri, M., et al., Gabapentin and pregabalin for the acute post-operative pain management. A systematic-narrative review of the recent clinical evidences. Curr Drug Targets, 2009. 10(8): p. 716-33.

39. Singh, D. and D.H. Kennedy, The use of gabapentin for the treatment of postherpetic neuralgia. Clin Ther, 2003. 25(3): p. 852-89.

40. Wiffen, P.J., et al., Gabapentin for chronic neuropathic pain in adults. Cochrane Database Syst Rev, 2017. 6: p. CD007938.

41. Moore, A., S. Derry, and P. Wiffen, Gabapentin for Chronic Neuropathic Pain. JAMA, 2018. 319(8): p. 818-819.

42. Mellegers, M.A., A.D. Furlan, and A. Mailis, Gabapentin for neuropathic pain: systematic review of controlled and uncontrolled literature. Clin J Pain, 2001. 17(4): p. 284-95.

43. Bar Ad, V., et al., Gabapentin for the treatment of pain syndrome related to radiationinduced mucositis in patients with head and neck cancer treated with concurrent chemoradiotherapy. Cancer, 2010. 116(17): p. 4206-13.

44. Bone, M., P. Critchley, and D.J. Buggy, Gabapentin in postamputation phantom limb pain: a randomized, double-blind, placebo-controlled, cross-over study. Reg Anesth Pain Med, 2002. 27(5): p. 481-6.

45. Surges, R. and T.J. Feuerstein, Mode of action of gabapentin in chronic neuropathic pain syndromes. A short review about its cellular mechanisms in nociceptive neurotransmission. Arzneimittelforschung, 2002. 52(8): p. 583-6.

46. Andrade, C., Gabapentin for Alcohol-Related Disorders: Critical Appraisal of the Symptom-Driven Approach. J Clin Psychiatry, 2020. 81(6).

47. Anton, R.F., et al., Efficacy of Gabapentin for the Treatment of Alcohol Use Disorder in Patients With Alcohol Withdrawal Symptoms: A Randomized Clinical Trial. JAMA Intern Med, 2020. 180(5): p. 728-736.

48. Falk, D.E., et al., Gabapentin Enacarbil Extended-Release for Alcohol Use Disorder: A Randomized, Double-Blind, Placebo-Controlled, Multisite Trial Assessing Efficacy and Safety. Alcohol Clin Exp Res, 2019. 43(1): p. 158-169.

49. Furieri, F.A. and E.M. Nakamura-Palacios, Gabapentin reduces alcohol consumption and craving: a randomized, double-blind, placebo-controlled trial. J Clin Psychiatry, 2007. 68(11): p. 1691-700.

50. Kranzler, H.R., et al., A meta-analysis of the efficacy of gabapentin for treating alcohol use disorder. Addiction, 2019. 114(9): p. 1547-1555.

51. Mariani, J.J., et al., Pilot randomized placebo-controlled clinical trial of high-dose gabapentin for alcohol use disorder. Alcohol Clin Exp Res, 2021. 45(8): p. 1639-1652.

52. Prisciandaro, J.J., et al., Effects of Gabapentin on Dorsal Anterior Cingulate Cortex GABA and Glutamate Levels and Their Associations With Abstinence in Alcohol Use Disorder: A Randomized Clinical Trial. Am J Psychiatry, 2021. 178(9): p. 829-837.

53. Swift, R.M. and E.R. Aston, Pharmacotherapy for alcohol use disorder: current and emerging therapies. Harv Rev Psychiatry, 2015. 23(2): p. 122-33. 
54. Guindon, J. and A.G. Hohmann, The endocannabinoid system and pain. CNS Neurol Disord Drug Targets, 2009. 8(6): p. 403-21.

55. Woodhams, S.G., et al., The cannabinoid system and pain. Neuropharmacology, 2017. 124: p. 105-120.

56. Sagar, D.R., et al., Dynamic regulation of the endocannabinoid system: implications for analgesia. Mol Pain, 2009. 5: p. 59.

57. Drew, G.M., B.K. Lau, and C.W. Vaughan, Substance $P$ drives endocannabinoid-mediated disinhibition in a midbrain descending analgesic pathway. J Neurosci, 2009. 29(22): p. 7220-9.

58. Ghosh, S., et al., The monoacylglycerol lipase inhibitor JZL184 suppresses inflammatory pain in the mouse carrageenan model. Life Sci, 2013. 92(8-9): p. 498-505.

59. Brindisi, M., et al., Development and Pharmacological Characterization of Selective Blockers of 2-Arachidonoyl Glycerol Degradation with Efficacy in Rodent Models of Multiple Sclerosis and Pain. J Med Chem, 2016. 59(6): p. 2612-32.

60. Burston, J.J., et al., Robust anti-nociceptive effects of monoacylglycerol lipase inhibition in a model of osteoarthritis pain. Br J Pharmacol, 2016. 173(21): p. 3134-3144.

61. Hohmann, A.G., Inhibitors of monoacylglycerol lipase as novel analgesics. $\mathrm{Br} J$ Pharmacol, 2007. 150(6): p. 673-5.

62. Guindon, J., et al., Peripheral antinociceptive effects of inhibitors of monoacylglycerol lipase in a rat model of inflammatory pain. Br J Pharmacol, 2011. 163(7): p. 1464-78.

63. Kinsey, S.G., et al., Blockade of endocannabinoid-degrading enzymes attenuates neuropathic pain. J Pharmacol Exp Ther, 2009. 330(3): p. 902-10.

64. Khasabova, I.A., et al., Increasing 2-arachidonoyl glycerol signaling in the periphery attenuates mechanical hyperalgesia in a model of bone cancer pain. Pharmacol Res, 2011. 64(1): p. 60-7.

65. Khasabova, I.A., et al., JZL184 is anti-hyperalgesic in a murine model of cisplatin-induced peripheral neuropathy. Pharmacol Res, 2014. 90: p. 67-75.

66. Thomas, A., et al., Peripheral deficiency and antiallodynic effects of 2-arachidonoyl glycerol in a mouse model of paclitaxel-induced neuropathic pain. Biomed Pharmacother, 2020. 129: p. 110456.

67. Deuis, J.R., L.S. Dvorakova, and I. Vetter, Methods Used to Evaluate Pain Behaviors in Rodents. Front Mol Neurosci, 2017. 10: p. 284.

68. Neurobehavioral, T.J.L.M. and P.F. (JAX-MNBF), Standard Operating Procedure von Frey Test

[VFT], in von Frey Test. 2018, The Jackson Laboratory: Bar Harbor, ME. p. 10.

69. Hermanson, D.J.a.H.N.D.a.G.-G.J.a.B.N.a.S.B.C.a.K.P.J.a.C.R.J.a.R.J., Substrate-selective COX-2 inhibition decreases anxiety via endocannabinoid activation. Nature Neuroscience, 2013. 16(9): p. 1291--1298.

70. Riittinen, M.L., et al., Impoverished rearing conditions increase stress-induced irritability in mice. Dev Psychobiol, 1986. 19(2): p. 105-11.

71. Kononoff, J., et al., Adolescent cannabinoid exposure induces irritability-like behavior and cocaine cross-sensitization without affecting the escalation of cocaine selfadministration in adulthood. Sci Rep, 2018. 8(1): p. 13893. 
72. Lagerspetz, K. and R. Portin, Simulation of cues eliciting aggressive responses in mice at two age levels. J Genet Psychol, 1968. 113(1st Half): p. 53-63.

73. Maybury, M.T., Multimedia Annotation, Querying, and Analysis in Anvil. 2012, Wiley: Hoboken, NJ, USA. p. 351-367.

74. Morgan, A., et al., Cyclooxygenase-2 inhibition reduces anxiety-like behavior and normalizes enhanced amygdala glutamatergic transmission following chronic oral corticosterone treatment. Neurobiol Stress, 2019. 11: p. 100190.

75. Ignatowska-Jankowska, B.M., et al., A Cannabinoid CB1 Receptor-Positive Allosteric Modulator Reduces Neuropathic Pain in the Mouse with No Psychoactive Effects. Neuropsychopharmacology, 2015. 40(13): p. 2948-59.

76. Crowe, M.S., et al., The monoacylglycerol lipase inhibitor KML29 with gabapentin synergistically produces analgesia in mice. Br J Pharmacol, 2017. 174(23): p. 4523-4539.

77. Curry, Z.A., et al., Monoacylglycerol Lipase Inhibitors Reverse Paclitaxel-Induced Nociceptive Behavior and Proinflammatory Markers in a Mouse Model of Chemotherapy-Induced Neuropathy. J Pharmacol Exp Ther, 2018. 366(1): p. 169-183.

78. Philpott, H.T. and J.J. McDougall, Combatting joint pain and inflammation by dual inhibition of monoacylglycerol lipase and cyclooxygenase-2 in a rat model of osteoarthritis. Arthritis Res Ther, 2020. 22(1): p. 9.

79. Lomazzo, E., et al., Therapeutic potential of inhibitors of endocannabinoid degradation for the treatment of stress-related hyperalgesia in an animal model of chronic pain. Neuropsychopharmacology, 2015. 40(2): p. 488-501.

80. Gianessi, C.A., S.M. Groman, and J.R. Taylor, Bi-directional modulation of food habit expression by the endocannabinoid system. Eur J Neurosci, 2019. 49(12): p. 1610-1622.

81. Oleson, E.B., et al., Endocannabinoids shape accumbal encoding of cue-motivated behavior via CB1 receptor activation in the ventral tegmentum. Neuron, 2012. 73(2): $p$. 360-73.

82. Winters, N.D., et al., Targeting diacylglycerol lipase reduces alcohol consumption in preclinical models. J Clin Invest, 2021.

83. Holleran, K.M., et al., Ketamine and MAG Lipase Inhibitor-Dependent Reversal of Evolving Depressive-Like Behavior During Forced Abstinence From Alcohol Drinking. Neuropsychopharmacology, 2016. 41(8): p. 2062-71.

84. Jiang, S.K., et al., The monoacylglycerol lipase inhibitor JZL184 decreases inflammatory response in skeletal muscle contusion in rats. Eur J Pharmacol, 2015. 761: p. 1-10.

85. Elphick, M.R. and M. Egertová, The neurobiology and evolution of cannabinoid signalling. Philos Trans R Soc Lond B Biol Sci, 2001. 356(1407): p. 381-408.

86. Patel, S., et al., The endocannabinoid system as a target for novel anxiolytic drugs. Neurosci Biobehav Rev, 2017. 76(Pt A): p. 56-66.

87. Atwood, B.K., A. Straiker, and K. Mackie, $\mathrm{CB}_{2}$ : therapeutic target-in-waiting. Prog Neuropsychopharmacol Biol Psychiatry, 2012. 38(1): p. 16-20.

88. Fernández-Ruiz, J., et al., Cannabinoid CB2 receptor: a new target for controlling neural cell survival? Trends Pharmacol Sci, 2007. 28(1): p. 39-45.

89. Parolaro, D., Presence and functional regulation of cannabinoid receptors in immune cells. Life Sci, 1999. 65(6-7): p. 637-44. 
90. Bisogno, T., et al., Cloning of the first sn1-DAG lipases points to the spatial and temporal regulation of endocannabinoid signaling in the brain. J Cell Biol, 2003. 163(3): p. 463-8.

91. Tanimura, A., et al., The endocannabinoid 2-arachidonoylglycerol produced by diacylglycerol lipase alpha mediates retrograde suppression of synaptic transmission. Neuron, 2010. 65(3): p. 320-7.

92. Shonesy, B.C., et al., Genetic disruption of 2-arachidonoylglycerol synthesis reveals a key role for endocannabinoid signaling in anxiety modulation. Cell Rep, 2014. 9(5): p. 16441653.

93. Ogasawara, D., et al., Rapid and profound rewiring of brain lipid signaling networks by acute diacylglycerol lipase inhibition. Proc Natl Acad Sci U S A, 2016. 113(1): p. 26-33.

94. Shonesy, B.C., et al., Genetic disruption of 2-arachidonoylglycerol synthesis reveals a key role for endocannabinoid signaling in anxiety modulation. Cell Rep, 2014. 9(5): p. 16441653.

95. Jenniches, I., et al., Anxiety, Stress, and Fear Response in Mice With Reduced Endocannabinoid Levels. Biol Psychiatry, 2016. 79(10): p. 858-868.

96. Bluett, R.J., et al., Endocannabinoid signalling modulates susceptibility to traumatic stress exposure. Nat Commun, 2017. 8: p. 14782.

97. Cavener, V.S., et al., Inhibition of Diacylglycerol Lipase Impairs Fear Extinction in Mice. Front Neurosci, 2018. 12: p. 479.

98. Wilkerson, J.L., et al., Investigation of Diacylglycerol Lipase Alpha Inhibition in the Mouse Lipopolysaccharide Inflammatory Pain Model. J Pharmacol Exp Ther, 2017. 363(3): p. 394-401.

99. Morgan, A.J., et al., Detection of Cyclooxygenase-2-Derived Oxygenation Products of the Endogenous Cannabinoid 2-Arachidonoylglycerol in Mouse Brain. ACS Chem Neurosci, 2018. 9(7): p. 1552-1559.

100. Britt, R.D., et al., Lipopolysaccharide-induced cyclooxygenase-2 expression in mouse transformed Clara cells. Cell Physiol Biochem, 2012. 29(1-2): p. 213-22.

101. Eguchi, M., et al., Lipopolysaccharide induces proinflammatory cytokines and chemokines in experimental otitis media through the prostaglandin D2 receptor (DP)dependent pathway. Clin Exp Immunol, 2011. 163(2): p. 260-9.

102. Zhao, J., et al., Neuroinflammation induced by lipopolysaccharide causes cognitive impairment in mice. Sci Rep, 2019. 9(1): p. 5790.

103. Levine, A., et al., DAGL $\alpha$ Inhibition as a Non-invasive and Translational Model of Episodic Headache. Front Pharmacol, 2020. 11: p. 615028.

104. Meng, I.D., et al., An analgesia circuit activated by cannabinoids. Nature, 1998. 395(6700): p. 381-3.

105. Martin, W.J., A.G. Hohmann, and J.M. Walker, Suppression of noxious stimulus-evoked activity in the ventral posterolateral nucleus of the thalamus by a cannabinoid agonist: correlation between electrophysiological and antinociceptive effects. J Neurosci, 1996. 16(20): p. 6601-11.

106. Kelly, S. and V. Chapman, Selective cannabinoid CB1 receptor activation inhibits spinal nociceptive transmission in vivo. J Neurophysiol, 2001. 86(6): p. 3061-4.

107. Hohmann, A.G., et al., Inhibition of noxious stimulus-evoked activity of spinal cord dorsal horn neurons by the cannabinoid WIN 55,212-2. Life Sci, 1995. 56(23-24): p. 2111-8. 
108. Drew, L.J., et al., Activation of spinal cannabinoid 1 receptors inhibits $C$-fibre driven hyperexcitable neuronal responses and increases [35S]GTPgammaS binding in the dorsal horn of the spinal cord of noninflamed and inflamed rats. Eur J Neurosci, 2000. 12(6): p. 2079-86.

109. Calignano, A., et al., Control of pain initiation by endogenous cannabinoids. Nature, 1998. 394(6690): p. 277-81.

110. Strangman, N.M., et al., Evidence for a role of endogenous cannabinoids in the modulation of acute and tonic pain sensitivity. Brain Res, 1998. 813(2): p. 323-8.

111. Richardson, J.D., L. Aanonsen, and K.M. Hargreaves, Hypoactivity of the spinal cannabinoid system results in NMDA-dependent hyperalgesia. J Neurosci, 1998. 18(1): p. 451-7.

112. Hohmann, A.G., et al., An endocannabinoid mechanism for stress-induced analgesia. Nature, 2005. 435(7045): p. 1108-12.

113. Centanni, S.W., et al., Endocannabinoid control of the insular-bed nucleus of the stria terminalis circuit regulates negative affective behavior associated with alcohol abstinence. Neuropsychopharmacology, 2019. 44(3): p. 526-537.

114. Xiao, H.W., et al., Gut microbiota modulates alcohol withdrawal-induced anxiety in mice. Toxicol Lett, 2018. 287: p. 23-30.

115. Brown, A.P., N. Dinger, and B.S. Levine, Stress produced by gavage administration in the rat. Contemp Top Lab Anim Sci, 2000. 39(1): p. 17-21.

116. Gonzales, C., et al., Alternative method of oral administration by peanut butter pellet formulation results in target engagement of BACE1 and attenuation of gavage-induced stress responses in mice. Pharmacol Biochem Behav, 2014. 126: p. 28-35.

117. Baldwin, H.A., et al., CRF antagonist reverses the "anxiogenic" response to ethanol withdrawal in the rat. Psychopharmacology (Berl), 1991. 103(2): p. 227-32.

118. Rassnick, S., et al., Microinjection of a corticotropin-releasing factor antagonist into the central nucleus of the amygdala reverses anxiogenic-like effects of ethanol withdrawal. Brain Res, 1993. 605(1): p. 25-32.

119. Metten, P., et al., An alcohol withdrawal test battery measuring multiple behavioral symptoms in mice. Alcohol, 2018. 68: p. 19-35.

120. Bhattacharya, S.K., et al., Rat brain monoamine oxidase $A$ and B inhibitory (tribulin) activity during drug withdrawal anxiety. Neurosci Lett, 1995. 199(2): p. 103-6.

121. File, S.E., Chronic exposure to noise modifies the anxiogenic response, but not the hypoactivity, detected on withdrawal from chronic ethanol treatment. Psychopharmacology (Berl), 1994. 116(3): p. 369-72.

122. File, S.E., N. Andrews, and M. al-Farhan, Anxiogenic responses of rats on withdrawal from chronic ethanol treatment: effects of tianeptine. Alcohol Alcohol, 1993. 28(3): p. 281-6.

123. File, S.E., A. Zharkovsky, and K. Gulati, Effects of baclofen and nitrendipine on ethanol withdrawal responses in the rat. Neuropharmacology, 1991. 30(2): p. 183-90.

124. Kliethermes, C.L., Anxiety-like behaviors following chronic ethanol exposure. Neurosci Biobehav Rev, 2005. 28(8): p. 837-50. 
125. Lee, K.M., et al., mGlu5 Receptor Blockade Within the Nucleus Accumbens Shell Reduces Behavioral Indices of Alcohol Withdrawal-Induced Anxiety in Mice. Front Pharmacol, 2018. 9: p. 1306.

126. Kliethermes, C.L., K. Cronise, and J.C. Crabbe, Anxiety-like behavior in mice in two apparatuses during withdrawal from chronic ethanol vapor inhalation. Alcohol Clin Exp Res, 2004. 28(7): p. 1012-9.

127. Glover, E.J., et al., Inhibition of the rostromedial tegmental nucleus reverses alcohol withdrawal-induced anxiety-like behavior. Neuropsychopharmacology, 2019. 44(11): p. 1896-1905.

128. Quadir, S.G., et al., Effect of different standard rodent diets on ethanol intake and associated allodynia in male mice. Alcohol, 2020. 87: p. 17-23.

129. Quadir, S.G., et al., Antagonism of Sigma-1 receptor blocks heavy alcohol drinking and associated hyperalgesia in male mice. Alcohol Clin Exp Res, 2021. 45(7): p. 1398-1407.

130. Koob, G.F. and M. Le Moal, Drug addiction, dysregulation of reward, and allostasis. Neuropsychopharmacology, 2001. 24(2): p. 97-129.

131. Koob, G.F. and N.D. Volkow, Neurocircuitry of addiction. Neuropsychopharmacology, 2010. 35(1): p. 217-38.

132. Koob, G.F. and M. Le Moal, Plasticity of reward neurocircuitry and the 'dark side' of drug addiction. Nat Neurosci, 2005. 8(11): p. 1442-4.

133. Clemmesen, L., et al., Brain marker protein changes after short-and long-term ethanol intoxication and withdrawal in the rat. J Psychiatr Res, 1987. 21(2): p. 171-83.

134. Clemmesen, L., et al., Local cerebral glucose consumption during ethanol withdrawal in the rat: effects of single and multiple episodes and previous convulsive seizures. Brain Res, 1988. 453(1-2): p. 204-14.

135. Ulrichsen, J., et al., The effect of phenobarbital and carbamazepine on the ethanol withdrawal reaction in the rat. Psychopharmacology (Berl), 1986. 89(2): p. 162-6.

136. Ulrichsen, J., L. Clemmesen, and R. Hemmingsen, Convulsive behaviour during alcohol dependence: discrimination between the role of intoxication and withdrawal. Psychopharmacology (Berl), 1992. 107(1): p. 97-102.

137. Kimbrough, A., et al., CRF. Alcohol Clin Exp Res, 2017. 41(11): p. 1886-1895.

138. de Guglielmo, G., et al., Dopamine D. Front Behav Neurosci, 2019. 13: p. 292.

139. Cippitelli, A., et al., Increase of brain endocannabinoid anandamide levels by FAAH inhibition and alcohol abuse behaviours in the rat. Psychopharmacology (Berl), 2008. 198(4): p. 449-60.

140. Vinod, K.Y., et al., Manipulation of fatty acid amide hydrolase functional activity alters sensitivity and dependence to ethanol. J Neurochem, 2008. 104(1): p. 233-43.

141. Grim, T.W., et al., Combined inhibition of FAAH and COX produces enhanced antiallodynic effects in mouse neuropathic and inflammatory pain models. Pharmacol Biochem Behav, 2014. 124: p. 405-11.

142. Marrs, W.R., et al., The serine hydrolase ABHD6 controls the accumulation and efficacy of 2-AG at cannabinoid receptors. Nat Neurosci, 2010. 13(8): p. 951-7.

143. Wen, J., et al., WWL70 protects against chronic constriction injury-induced neuropathic pain in mice by cannabinoid receptor-independent mechanisms. J Neuroinflammation, 2018. 15(1): p. 9. 
bioRxiv preprint doi: https://doi.org/10.1101/2022.02.15.480609; this version posted February 17, 2022. The copyright holder for this preprint (which was not certified by peer review) is the author/funder. All rights reserved. No reuse allowed without permission.

144. Tanaka, M., et al., WWL70 attenuates PGE. J Neuroinflammation, 2017. 14(1): p. 7. 
A

\begin{tabular}{|c|c|c|c|c|}
\hline Water & 3 weeks & $\downarrow \begin{array}{l}\text { Von Frey } \\
\text { Hot Plate }\end{array}$ & $\begin{array}{l}\text { Von Frey } \\
\text { Hot Plate }\end{array}$ & لـ $\begin{array}{l}\text { Von Frey } \\
\text { Hot Plate }\end{array}$ \\
\hline \multicolumn{5}{|l|}{ or } \\
\hline Alcoho & (2-bottle choice) & 24h withdrawal & 72h withdrawal & $7 \mathrm{~d}$ withdrawal \\
\hline
\end{tabular}

B

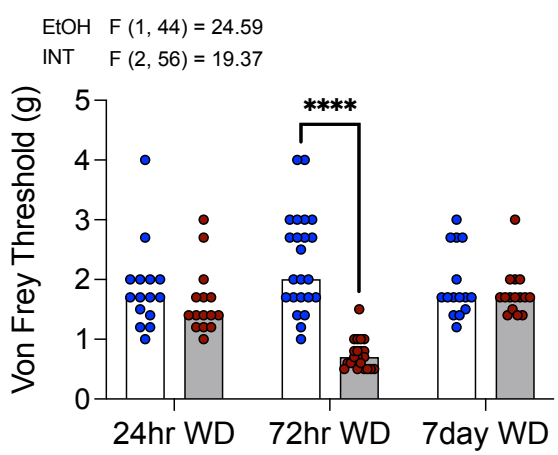

D

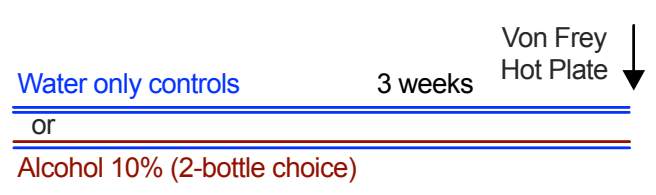

C EtOH $F(1,28)=0.2089 \quad P=0.6512$

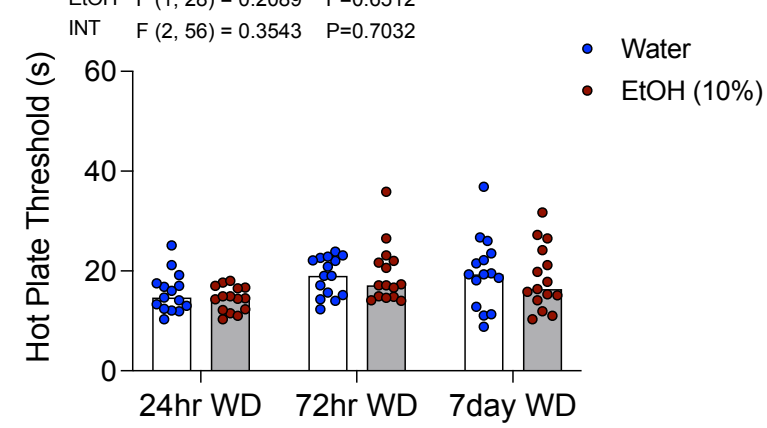

$E$

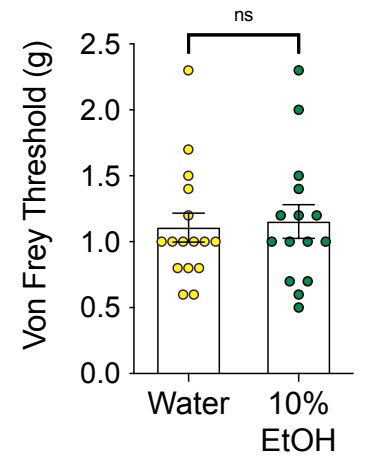

$\mathbf{F}$

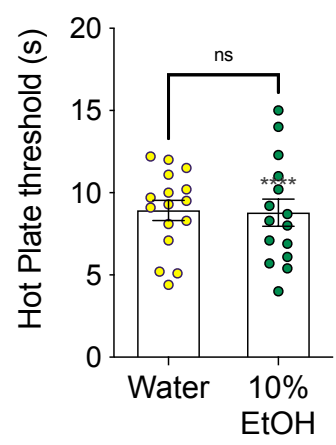

Figure 1. Alcohol withdrawal produces transient mechanical but not thermal hypersensitivity

(A) Schematic of 21-day 2BC EtOH drinking paradigm and behavioral testing at withdrawal time points. (B) Mechanical hypersensitivity is seen only at the 72-hour EtOH withdrawal time point, with reduced Von Frey threshold compared to water-drinking controls. (C) No effects on thermal sensitivity were observed at any withdrawal timepoint measured by the Hot Plate test. (D) Schematic of pain testing during drinking $10 \% \mathrm{EtOH}$ or water-only. No effect on (E) Von Frey or (F) Hot Plate threshold was observed during drinking. F-scores on graphs represent main effects or interactions from Two-Way ANOVAs. $* * * *$ p $<0.0001$ via post-hoc Holm-Sidak pairwise comparisons. Data presented as individual female mice and Mean \pm SEM. NS; not significant. 
A

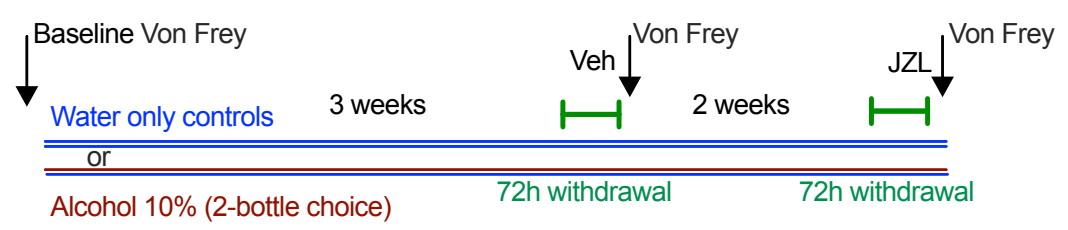

B

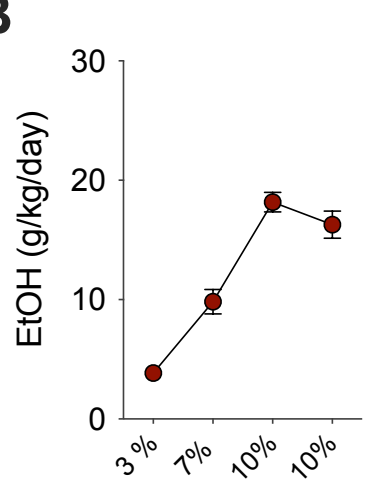

C

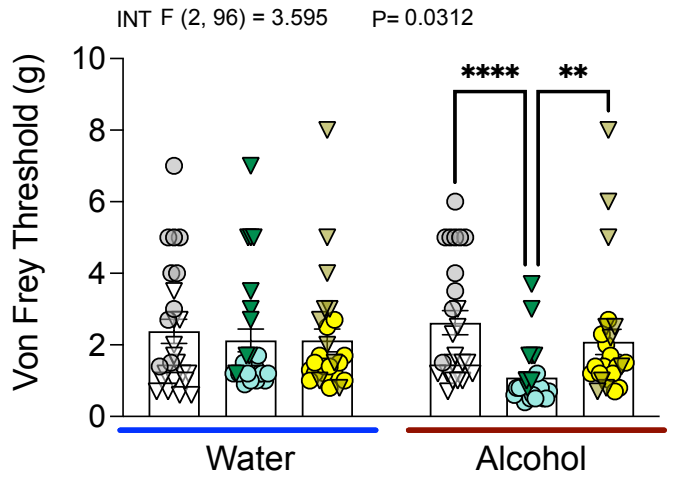

O Baseline

- $72 \mathrm{hr}$ WD-Vehicle

○ $72 \mathrm{hr}$ WD-JZL

D

\begin{tabular}{cc|ccc} 
3 weeks & Veh or JZL Von Frey & 2 weeks \\
\hline \hline Alcohol 10\% (2-bottle choice) & $72 \mathrm{~h}$ withdrawal & Alcohol $20 \%$ & $72 \mathrm{~h}$ withdrawal
\end{tabular}

E

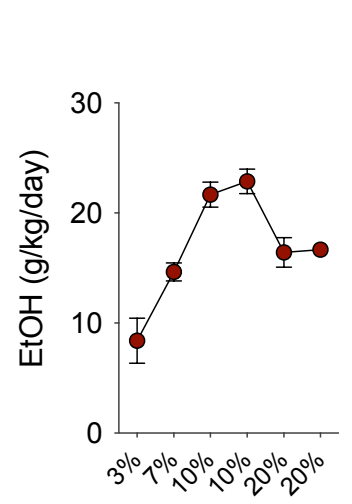

$\mathbf{F}$

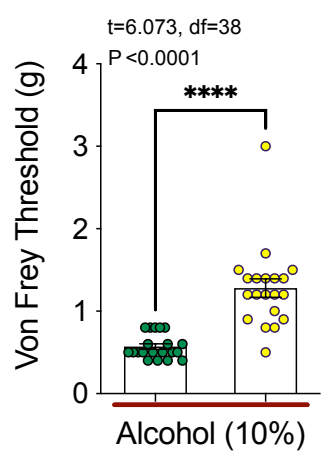

G

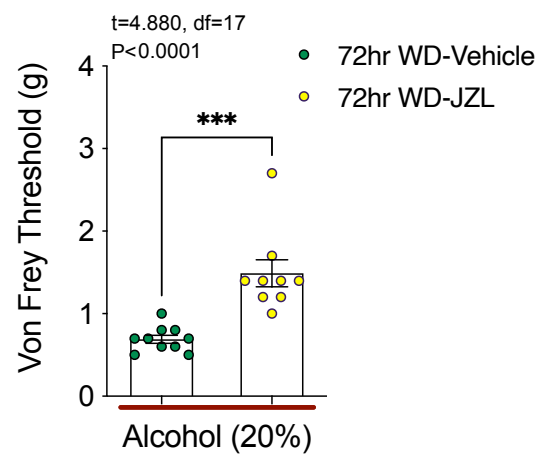

Figure 2. JZL184 reverses mechanical hypersensitivity at 72 hours EtOH withdrawal

(A) Schematic of experimental timeline. (B) Weekly EtOH intake of alcohol-drinking mice. (C) Von Frey threshold is significantly reduced at 72 hours EtOH withdrawal, which is prevented by JZL184. (D) Schematic experimental timeline. (E) Weekly EtOH intake of alcohol-drinking mice. (F-G) JZL184 reverses mechanical hypersensitivity at 72 hours EtOH withdrawal from 10\% and $20 \% \mathrm{EtOH}$. F and t statistics shown in figures from 2-Away ANOVA interaction and unpaired ttests. $* * \mathrm{p}<0.01, * * * \mathrm{p}<0.001, * * * * \mathrm{p}<0.0001$ via post-hoc Holm-Sidak pairwise comparisons or $\mathrm{t}$-test. Data presented as individual mice (triangles males and circles females) and Mean \pm SEM. 


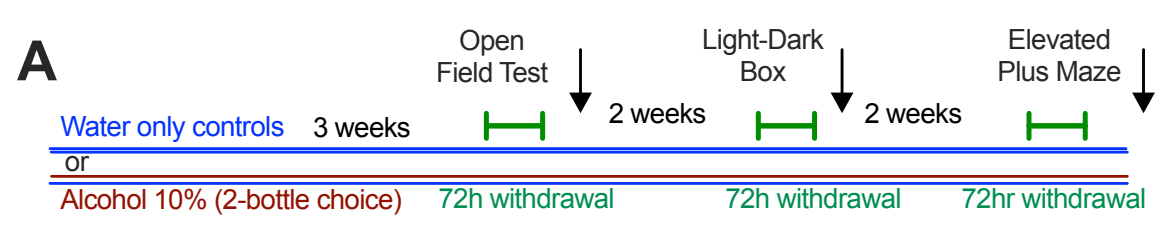

B Open Field
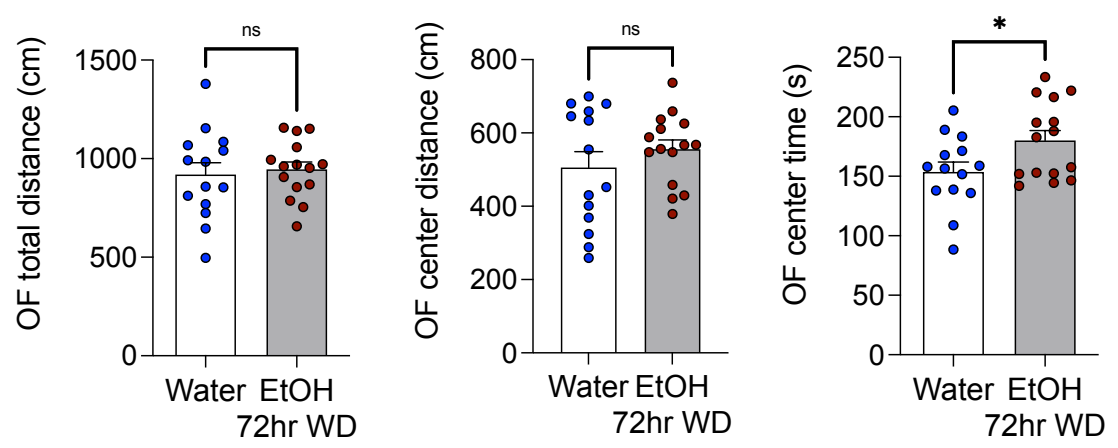

\section{Light-Dark}
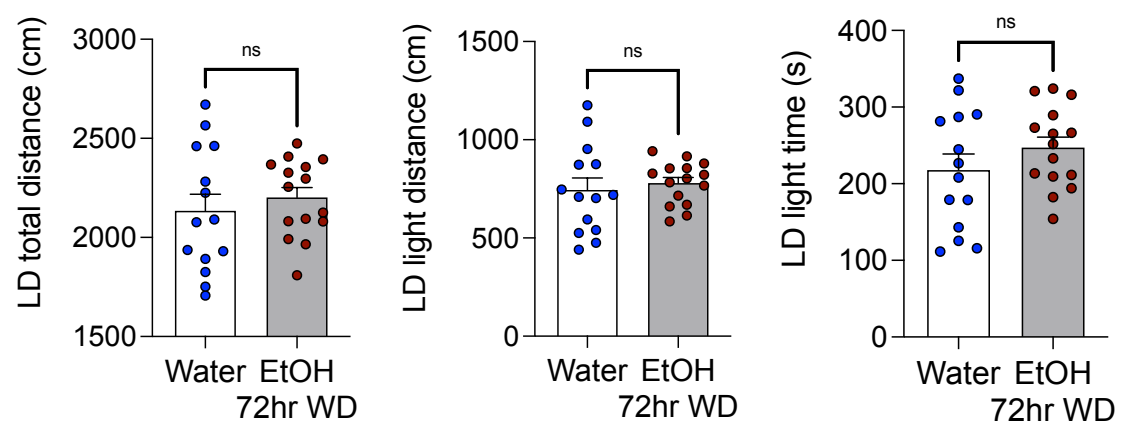

D Elevated Plus Maze
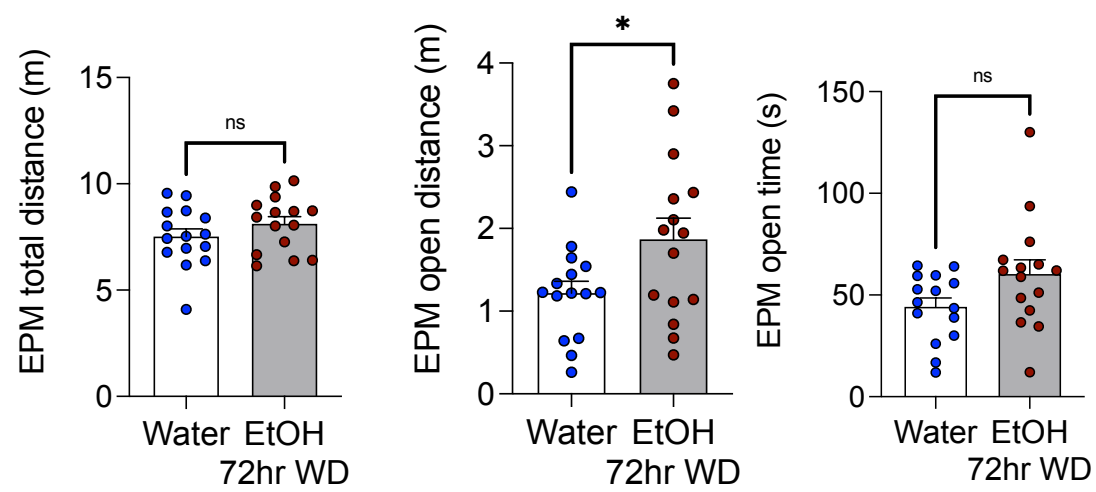

Figure 3. EtOH withdrawal does not increase anxiety-like behaviors

Schematic of experimental timeline. (B) Effects of 72-hour EtOH withdrawal on Open Field test. (C) Effects of 72-hour EtOH withdrawal on Light-Dark test. (D) Effects of 72-hour EtOH withdrawal on Elevated Plus Maze. ${ }^{* *} \mathrm{p}<0.01$, via t-test. Data presented as individual female mice and Mean \pm SEM. 

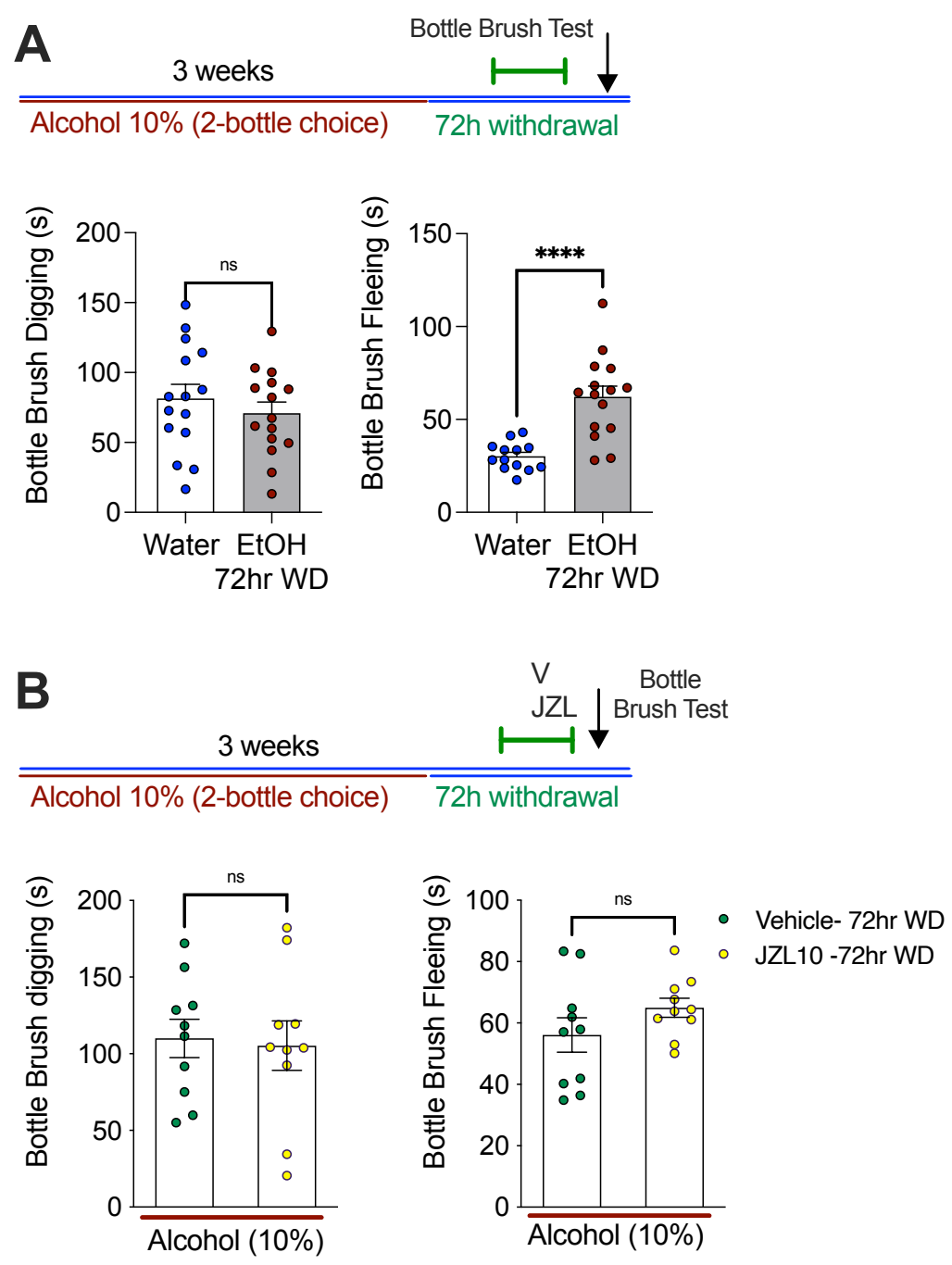

Figure 4. EtOH withdrawal increases irritability behavior, which is not prevented by JZL184. A. Schematic of 2BC drinking with irritability behavior tested at 72 hours EtOH withdrawal. (Left) 72-hour EtOH withdrawal had no effect on digging behavior in the bottle brush test, but (right) significantly increased fleeing behavior. B. A separate cohort was tested for irritability at 72-hours withdrawal and given vehicle or JZL-184. (Left) JZL-184 had no effect on digging or (right) fleeing in the bottle brush test. $* * * * \mathrm{p}<0.0001$ via t-test. Data presented as individual female mice and Mean \pm SEM. 

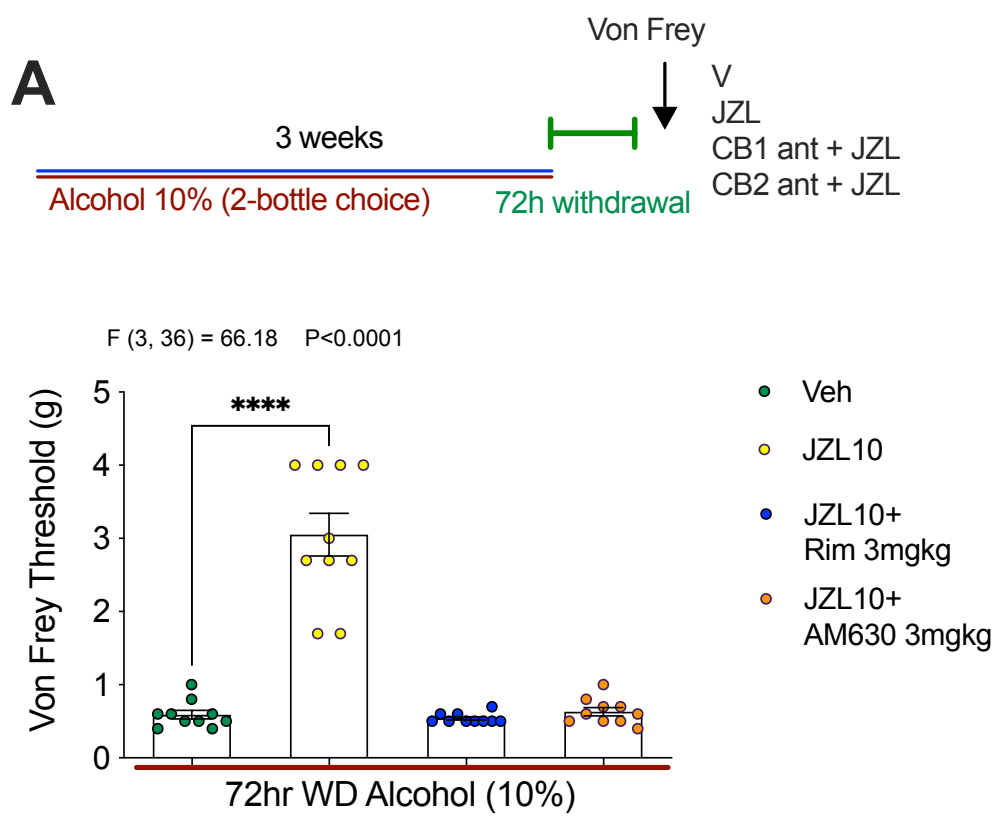

B $\begin{aligned} & \text { CB1 antagonist } \\ & \frac{\text { CB2 antagonist } 120 \mathrm{~min}}{\text { Water only }} \downarrow\end{aligned}$

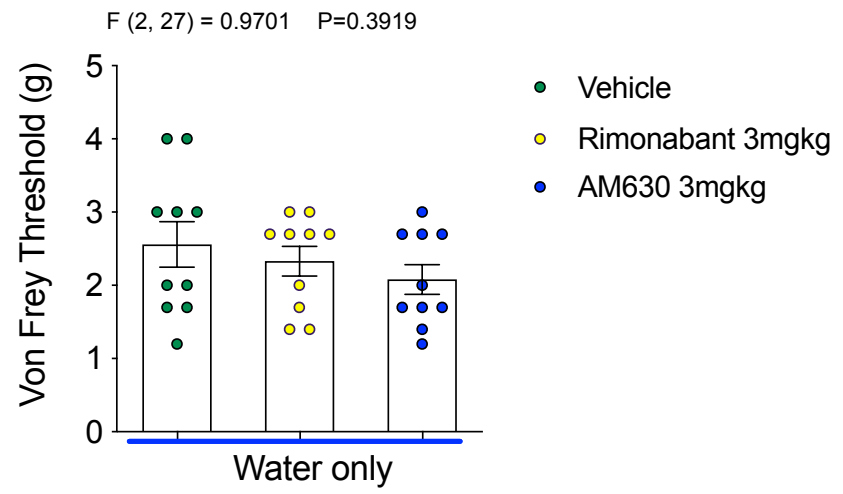

Figure 5. CB1 and CB2 receptor antagonists prevent the anti-hyperalgesic effects of JZL184 (A) Both Rimonabant and AM630 prevent the anti-hyperalgesic effects of JZL184. (B) Neither Rimonabant nor AM630 affect mechanical sensitivity thresholds in water drinking mice. F-scores on graphs represent main effects of ANOVA. ****p $<0.0001$ via post-hoc Holm-Sidak pairwise comparisons. Data presented as individual female mice and Mean \pm SEM. 

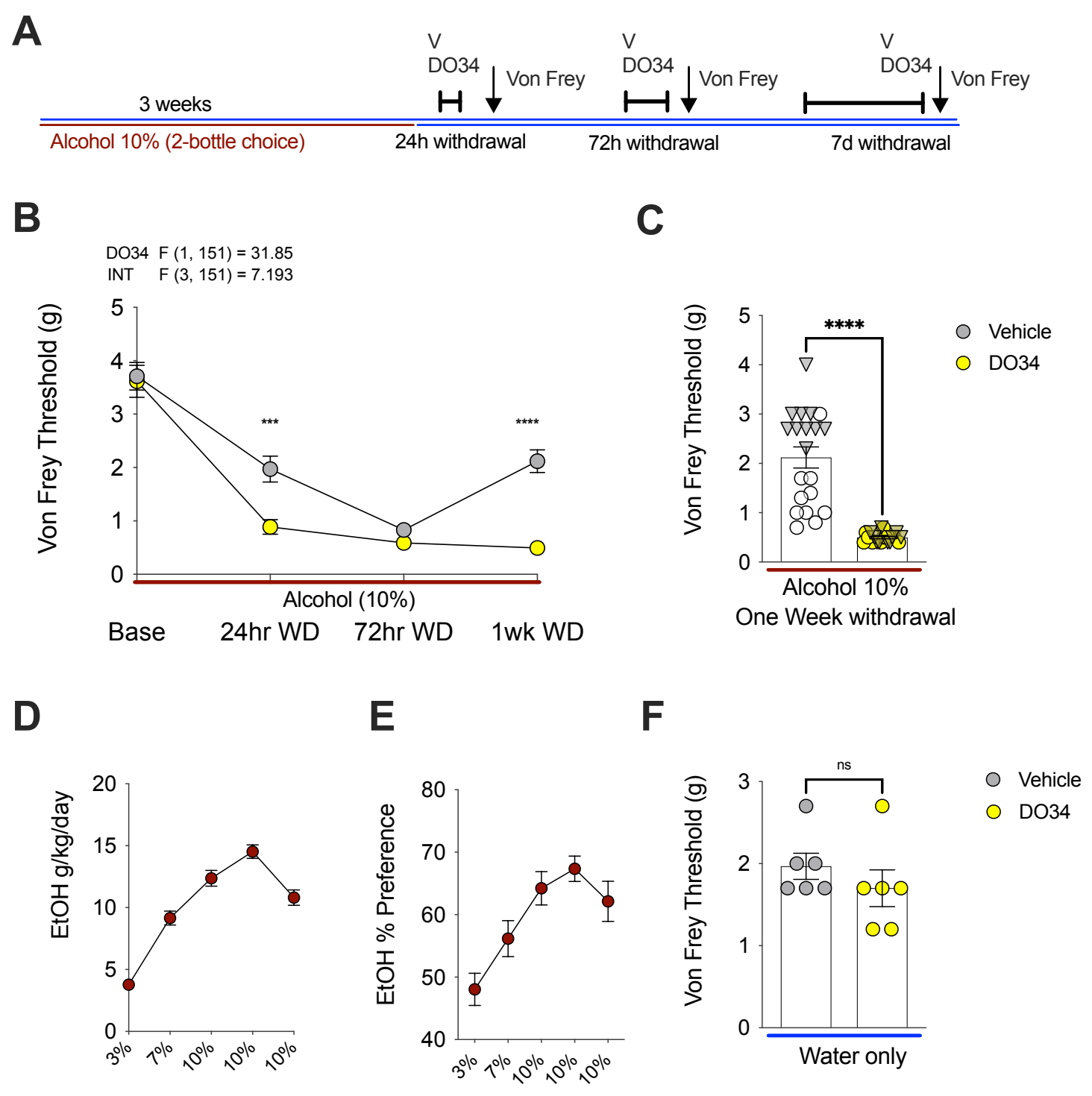

Figure 6. DO34 exacerbates mechanical hypersensitivity during EtOH withdrawal

(A) Schematic of experimental timeline and drug treatments. (B) DO34 decreased Von Frey threshold at 24-hours and one-week into $\mathrm{EtOH}$ withdrawal relative to vehicle-treated mice. (C) The same results at one week withdrawal separating males (circles) and female (triangles) data points. (D-E) Weekly EtOH intake and preference for mice shown in (B-C). (F) D034 does not affect sensitivity thresholds in water-only drinking mice. F-scores on graphs represent main effects and interaction from Two-way ANOVA. ***p $<0.001$, ****p $<0.0001$ via post-hoc Holm-Sidak pairwise comparisons or unpaired t-test. NS; not significant. Data presented as individual mice (triangles males and circles females) and Mean \pm SEM. 